\title{
LONGITUDINALIDADE DO CUIDADO: COMPREENSÃO DOS ENFERMEIROS QUE ATUAM NA ESTRATÉGIA SAÚDE DA FAMÍLIAa
}

\author{
Longitudinality of care: perceptions of the nurses that work at the family health strategy \\ Longitudinalidad de la atención: comprensión de los enfermeros que actúan en la estrategia \\ salud de la familia
}

\section{RESUMO}

Objetivou-se identificar como os enfermeiros conceituam a longitudinalidade do cuidado na Estratégia Saúde da Família e verificar sua compreensão sobre a efetivação dessa em seu trabalho e junto à equipe. Trata-se de um estudo descritivo-exploratório com abordagem qualitativa. Os dados foram coletados de 20 enfermeiros que atuam na saúde da família de municípios no âmbito da $10^{2}$ Regional de Saúde do Paraná, por meio de entrevistas semiestruturadas, no mês de abril de 2010, e submetidos à análise de conteúdo categorial. Os enfermeiros compreendem a longitudinalidade como algo duradouro, atendendo o indivíduo integralmente. Esse profissional assiste aos usuários nos diferentes ciclos de vida, e a equipe é participativa, com maior atuação do Agente Comunitário de Saúde e menor participação do médico. Conclui-se que a longitudinalidade é importante no trabalho da equipe de saúde da família, e que sua prática está em conformidade com os princípios do modelo assistencial em questão.

Palavras-chave: Saúde da família. Atenção primária à saúde. Continuidade da assistência ao paciente. Serviços de saúde. Enfermagem.

\section{Abstract}

This work was aimed to identify how the nurses consider the longitudinality of care in the Family Health Strategy (FHS) and to verify their perception on its effectiveness in their work as well as in the working team. This is a descriptive-exploratory study with qualitative approach. Data were collected from 20 nurses that work in the FHS within the $10^{\text {th }}$ Regional of Health of Paraná State, through semistructured recorded interviews in the month of April 2010 and submitted to the content analysis. The nurses understand the longitudinality of care as something durable, to assist the individuals in a thorough way. That kind of professional assists the users in their different life cycles, and the team is participative, with more actions from the part of the Community Agent of Health and less doctor's participation. It is concluded that the longitudinality of care is important in the work of the family health team, and that its practice is in agreement with the prevailing model of assistance.

Keywords: Family Health. Primary Health Care. Continuity of Patient Care. Health Services. Nursing.

\section{Resumen}

Tuvo por objetivo identificar cómo los enfermeros conceptúan la longitudinalidad del cuidado en la Estrategia Salud de la Familia y verificar su comprensión sobre la efectuación de ésa en su trabajo y junto al equipo. Se trata de un estudio descriptivo y exploratorio con abordaje cualitativo. Los datos fueron recogidos junto a 20 enfermeros que actúan en la salud de la familia de municipios en el ámbito de la $10^{a}$ Regional de Salud de Paraná, por medio de entrevistas semiestructuradas, en el mes de abril de 2010, y sometidos al análisis de contenido de categorías. Los enfermeros comprenden la longitudinalidad como algo duradero, atendiendo al individuo integralmente. Ese profesional asiste a los usuarios en los diferentes ciclos de vida, y el equipo es participativo, con mayor actuación del Agente Comunitario de Salud y menor participación del médico. Se concluye que la longitudinalidad es importante en el trabajo del equipo de salud de la familia, y que su práctica está en conformidad con los principios del modelo asistencial en cuestión.

Palabras clave: Salud de la familia. Atención Primaria de Salud. Continuidad de la Atención al Paciente. Servicios de Salud. Enfermería.

\footnotetext{
${ }^{1}$ Enfermeira. Mestre em Enfermagem pela Universidade Estadual de Maringá - UEM. Professora Colaboradora do Departamento de Enfermagem da Universidade Estadual do Centro-Oeste - UNICENTRO. Guarapuava - PR. Brasil. E-mail: baratieri.tatiane@gmail.com; ${ }^{2}$ Enfermeira. Dra. em Filosofia da Enfermagem. Professora da Pós-graduação em Enfermagem e em Ciências da Saúde da Universidade Estadual de Maringá - UEM. Maringá - PR. Brasil. E-mail: soniasilva.marcon@gmail.com
} 


\section{INTRODUÇÃO}

A Atenção Primária à Saúde (APS) passou a ser estruturada a partir da Conferência Internacional sobre Cuidados Primários de Saúde, realizada em 1978, em AlmaAta'. Assim, a APS busca implementar outros modelos de assistência, uma vez que o modelo centrado no hospital não atende às modificações do mundo moderno e às necessidades de saúde dos indivíduos e das famílias.

Foi a partir de 1988, no Brasil, com os debates realizados na $8^{a}$ Conferência Nacional de Saúde e, posteriormente, em espaços de articulação da Participação Popular na Constituinte, que se originou o Sistema Único de Saúde (SUS). ${ }^{1}$ Assim, com a histórica busca de mudanças no modelo de atenção à saúde, resultou, em 1994, no Programa Saúde da Família (PSF), apresentado como um modelo centrado na família e na equipe. ${ }^{2}$

Atualmente, o PSF é definido com a denominação de Estratégia Saúde da Família (ESF), tendo em vista seu caráter de reorganização da APS, e um modelo contínuo de atenção, ou seja, sem previsão de término. Sendo um modelo da APS, também é a porta de entrada no sistema de saúde para as necessidades e problemas de saúde da população, oferecendo atenção para a pessoa no decorrer do tempo, e para todas as condições, exceto as raras, além de coordenar ou integrar as ações fornecidas em outro lugar ou por terceiros. ${ }^{3}$

A APS distingue-se de outros níveis assistenciais por apresentar quatro atributos essenciais, sendo eles: a acessibilidade, a longitudinalidade, a integralidade e a coordenação.

Dentre esses atributos, todos eles importantes para a APS e, consequentemente, para a ESF, destaca-se a longitudinalidade, que significa o acompanhamento do usuário ao longo do tempo pela equipe de saúde, ${ }^{3}$ a qual constitui o foco deste estudo.

No Brasil, o termo longitudinalidade é pouco usado, e estudos sobre a atuação profissional nesse sentido são escassos. Na literatura internacional, o termo continuidade do cuidado é empregado com sentido similar. ${ }^{4}$ Apesar de a palavra continuidade ser corriqueiramente utilizada como sinônimo de longitudinalidade, esses termos possuem especificidades conceituais. Na APS a longitudinalidade é empregada para significar "uma relação pessoal de longa duração entre os profissionais de saúde e os pacientes em suas unidades de saúde". A continuidade não é necessária para que essa relação exista, pois interrupções na continuidade da atenção não significa interrupção da relação. 3:247

A longitudinalidade apresenta efeitos benéficos no sistema de saúde como o melhor reconhecimento das necessidades dos usuários, diagnóstico mais preciso, redução de custos e de hospitalizações, melhor prevenção e promoção da saúde, e maior satisfação do usuários. Assim, ao longo do tempo é estabelecida confiança entre profissional e usuário, deixando este mais confortável para expor seus problemas e acatar as recomendações. Do mesmo modo, quando o profissional possui um conhecimento acumulado sobre o usuário, chega-se mais rapidamente à avaliação do problema. ${ }^{3}$

Vale salientar que a longitudinalidade do cuidado ocorre com maior frequência em unidades de ESF do que em unidades tradicionais, conforme apresenta um estudo realizado em Petrópolis/RJ. Os dados apontam essa diferença, pois em ESF quase todas as unidades têm uma população geograficamente definida, enquanto clínicas tradicionais não têm, assim como os profissionais relatam que em ESF, em geral, há tempo suficiente para o usuário discutir suas dúvidas com o profissional de saúde, enquanto na unidade tradicional esse tempo é mais limitado. ${ }^{5}$

A ESF possui responsabilidade longitudinal pelos usuários da rede de serviços de saúde, mantendo relação constante com estes, ao longo da vida, e isso deve ocorrer independentemente da presença ou ausência de doença, garantindo-se o cuidado integral. ${ }^{3}$ No âmbito da ESF, tem-se a equipe mínima, que é composta pelo médico, enfermeiro, auxiliar ou técnico em enfermagem e agentes comunitários de saúde, a qual tem como uma de suas atuaç̃̃es a prestação de uma assistência longitudinal. Desses, o enfermeiro é um profissional que, junto com os demais membros da equipe, deve ter grande contato e conhecimento a respeito do território e das condições socioeconômicas da população atendida, assim como possuir um aporte prático e científico para atender aos usuários.

A prática profissional do enfermeiro na ESF é considerada de suma importância social, em especial no que se refere ao processo saúde-doença da população, e suas ações são muito importantes para se reestruturar esse modelo assistencial. ${ }^{6}$ Assim, esse artigo trata das interpretações de enfermeiros sobre a longitudinalidade, pois, ao revisar a literatura, e valorizar a importância de tal atributo, percebe-se a escassez de estudos - especialmente no Brasil - que abordem o tema, e, considerando que esse é importante na APS e, consequentemente, fundamental para a ESF, o presente estudo objetivou identificar como os enfermeiros conceituam a longitudinalidade do cuidado na ESF e verificar sua compreensão sobre a efetivação dessa em seu trabalho e junto à equipe.

\section{METODOLOGIA}

0 presente estudo, de natureza descritivoexploratória qualitativo, é parte do projeto de pesquisa " 0 trabalho assistencial e educativo no cotidiano do enfermeiro no PSF - características e desafios", apoiado financeiramente pela Fundação Araucária, realizado em sete dos 25 municípios integrantes da $10^{a}$ Regional de Saúde do Paraná, com sede em Cascavel/PR. 0 Estado do Paraná é dividido em 22 Regionais de Saúde, as quais constituem a instância administrativa intermediária da Secretaria de Saúde do Estado do Paraná com as secretarias municipais de saúde. 
Para a definição dos participantes do estudo, considerando a possibilidade de existir certa diversidade na ESF dos municípios da regional definida, relacionada ao seu porte populacional (ou seja, capacidades diferenciadas de atendimento à saúde, com influência nas possibilidades de prestação do atendimento (ongitudinal), esses foram inicialmente divididos em cinco grupos: os municípios que tinham menos de 5.000 habitantes (6); de 5.000 a 10.000 habitantes (10); de 10.000 a 20.000 habitantes (7); de 20.000 a 35.000 habitantes (1); e mais de 35.000 habitantes (1). Na sequência, sortearam-se dois municípios pertencentes aos três primeiros grupos e se incluíram os dois maiores.

Todos os enfermeiros atuantes na ESF dos municípios incluídos no estudo deveriam ser informantes deste, desde que atendessem aos seguintes critérios de inclusão: integrar uma equipe de ESF completa e estar atuando na mesma equipe há pelo menos cinco meses. Do total de 27 enfermeiros atuantes nas equipes de ESF nos municípios selecionados, 20 participaram do estudo, considerando que quatro não atendiam aos critérios de inclusão (dois atuavam na unidade há menos de cinco meses, e dois não tinham equipe mínima completa), um estava de férias, outro afastado por questões de saúde, e um terceiro não aceitou participar do estudo.

A coleta dos dados foi realizada no mês de abril de 2010, por meio de entrevistas, as quais após o consentimento foram gravadas em gravador tipo digital. As entrevistas foram previamente agendadas por telefone, conforme a disponibilidade de cada profissional e transcorreram em sala reservada. Assim, 16 foram realizadas nas unidades de saúde de cada município, três na secretaria de saúde de Cascavel, em dia de reunião, e uma na $10^{2}$ Regional de Saúde, em dia de capacitação.

As entrevistas foram norteadas por um roteiro semiestruturado composto por duas partes: a primeira, com questões objetivas referentes ao perfil sociodemográfico e à dinâmica de trabalho dos pesquisados; e a segunda, com questões abertas relacionadas com a compreensão do termo longitudinalidade do cuidado e como ela se dá no cotidiano de trabalho do enfermeiro e de sua equipe. Mediante a não clareza sobre o termo longitudinalidade do cuidado, o pesquisador esclareceu o conceito da expressão usada no estudo, para que esse pudesse embasar o restante da entrevista: "Refere-se, em especial, ao estabelecimento de relação terapêutica duradoura entre usuários e profissionais da equipe de saúde, ou seja, se trata do acompanhamento do usuário ao longo do tempo por profissionais da equipe" ${ }^{3}$.

$\mathrm{Na}$ discussão dos resultados, foram utilizados principalmente os pressupostos conceituais de Starfield ${ }^{3}, 0$ qual trata a longitudinalidade como uma das principais características da APS. A análise dos dados se deu por meio da análise de conteúdo categorial, procedendo-se a pré-análise mediante leituras flutuantes da totalidade dos dados coletados que se configurou no corpus analisado, viabilizando a formulação de interpretações e indagações iniciais. Em seguida, realizou-se leitura exaustiva do material, sua codificação, enumeração, classificação e agregação. Finalmente, procedeuse a interpretação e categorização dos resultados obtidos, diante da identificação das unidades de interesse, dos aspectos comuns entre elas e das inferências.?

0 desenvolvimento do estudo atendeu às exigências da Resolução 196/96 do Conselho Nacional de Saúde, e foi aprovado pelo Comitê Permanente de Ética em Pesquisa Envolvendo Seres Humanos da Universidade Estadual de Maringá (parecer n. 659/2009). Antes da entrevista as informações pertinentes ao estudo foram explanadas pelo pesquisador, com assinatura do Termo de Consentimento Livre e Esclarecido.

Para a diferenciação dos sujeitos da pesquisa, assim como a preservação de sua identidade, foram utilizados códigos, em que os enfermeiros foram referenciados com a letra ' $E$ ' seguida de numeral arábico, de acordo com a ordem das entrevistas (E1 a E20).

\section{RESULTADOS E DISCUSSÃO}

\section{Perfil Sociodemográfico e Dinâmica de Trabalho dos Enfermeiros em Estudo}

Entre os enfermeiros estudados, a maioria era do sexo feminino (19), com idade entre 22 e 45 anos, e a maior parte (11) estava na faixa etária dos 26 aos 30 anos. Dos respondentes, doze eram casados, seis solteiros, um separado judicialmente e um em união estável. A maior parte (11) não tinha filhos, cinco tinham dois filhos e quatro, um filho.

Dentre os 20 participantes, 18 atuavam apenas na ESF, um também atuava na área da docência e outro, na área hospitalar. A renda familiar mensal variou de 3 a 26 salários mínimos, predominando (14) uma renda de 5 a 10 salários; em oito casos apenas duas pessoas eram dependentes da renda, ressaltando que o número máximo de dependentes foi de cinco pessoas, representado por apenas um caso.

Em relação à formação dos enfermeiros, identificouse que a maior parte (13) se graduou em universidade pública, e o tempo de formação variou de 2 a 20 anos, sendo que seis se graduaram entre 10 e 20 anos, e os outros 14 enfermeiros, em menos de oito anos. Quase a totalidade dos enfermeiros (19) possuía pós-graduação lato sensu, sendo 15 na área de saúde pública, dos quais cinco em saúde da família.

Sobre a dinâmica de trabalho dos pesquisados, a maioria (15) atuava em unidade exclusiva de ESF e os outros cinco em unidades mistas. Quanto ao vínculo empregatício, 17 entrevistados realizaram concurso público e três eram seletistas. No que concerne ao tempo de atuação na ESF, variou de 5 meses a 12 anos; a metade (10) atua entre seis e dez anos, e o tempo de trabalho na mesma unidade variou de cinco meses a oito anos, predominando (10) a faixa de tempo de um a cinco anos. 
No tocante ao número de famílias atendidas pela equipe de ESF, a maioria (17) não ultrapassa o número preconizado para esse modelo assistencial, atendendo entre 500 e 1000 famílias. Dos entrevistados, 12 possuíam alguma área de seu território descoberta por ACS, variando de 100 a 250 famílias.

\section{A CONCEPCÃO DOS ENFERMEIROS SOBRE LONGITUDINALIDADE DO CUIDADO}

Dos relatos foi possível identificar duas vertentes conceituais para o termo longitudinalidade do cuidado, as quais são apresentadas a seguir: "o cuidado longitudinal como uma perspectiva duradoura" e "o cuidado longitudinal na perspectiva da integralidade da assistência".

\section{Cuidado Longitudinal como uma Perspectiva Duradoura}

0 termo longitudinalidade do cuidado não é muito difundido na literatura, especialmente no Brasil, o que justifica que a expressão não seja clara para a maioria dos entrevistados. $\mathrm{Na}$ concepção dos enfermeiros a expressão perpassa principalmente por um cuidado duradouro, que faz uma previsão não apenas para o cuidado presente, mas, sobretudo, pensando no desenvolvimento desse cuidado de forma porvindoura.

\begin{abstract}
Acho que essa longitudinalidade é abranger a saúde ao longo do tempo, não a curto prazo; a longo prazo, que se pensa lá na frente (E 5).
\end{abstract}

Acredito que o cuidado longitudinal seja uma assistencial prestada após a patologia, a assistência, ou seja, um cuidado prolongado (E 8).

A longitudinalidade do cuidado, que é o estabelecimento da relação terapêutica duradoura entre usuário e profissionais de saúde, de fato é um processo extenso e que demanda um grande período de tempo para ser operacionalizado, dependendo, especialmente da frequência de contato entre ambos. As respostas de entrevistados, apesar de serem objetivas, em virtude do pouco ou nenhum conhecimento prévio sobre a expressão, foram pertinentes ao abordar o fator tempo, que tem grande influência para a ocorrência da longitudinalidade.

Concorda-se com os pesquisados que o termo longitudinalidade é de difícil conceituação, o qual não é encontrado em qualquer dicionário. É derivado de longitudinal, definido como "lidar com o crescimento e as mudanças de indivíduos ou grupos no decorrer de um período de anos", 3:247 0 termo é associado a uma progressiva relação terapêutica entre usuário e um ou mais profissionais, em um mesmo local, o que aumenta o conhecimento sobre o indivíduo e oferece a percepção de garantia do cuidado futuro, além de ser pautada na confiança e responsabilidade entre profissional e usuário.,
Outro ponto abordado por respondentes, o qual remete ao significado da longitudinalidade a uma relação duradoura, foi a questão das ações preventivas, que são vistas como um processo que demanda tempo.

O cuidado ao longo do tempo é não só quando a pessoa esteja realmente com a patologia, mas que se faz o cuidado preventivo, o cuidado pós-patológico (E1).

Eu acredito que longitudinalidade seja em relação à prevenção, de você ver o paciente bem à frente, não só o momento [...] (E16).

A concepção que enfermeiros têm sobre o termo está em conformidade com o que tem sido encontrado na literatura, visto que um cuidado longitudinal engloba uma assistência integral, assistindo o usuário e vendo os resultados das ações prestadas. Esse cuidado deve permear um acompanhamento pelo profissional além dos episódios de doença, por meio de ações de prevenção, promoção e recuperação da saúde.

A longitudinalidade envolve, por exemplo, o acompanhamento dos diversos problemas de saúde de um usuário pela mesma equipe de saúde, e necessita manter uma estabilidade pessoal no tempo e espaço na inter-relação profissional/usuário para resolução dos problemas de saúde. ${ }^{10}$ Para tanto, é fundamental que o profissional desenvolva constantemente ações preventivas e de promoção da saúde junto à população adscrita, tendo em vista que é principalmente por meio dessas ações que as condições de saúde são melhoradas e mantidas, minimizando a exposição a fatores de risco, o que evita o surgimento de agravos.

As concepções sobre longitudinalidade do cuidado referidas pelos entrevistados podem ser influenciadas pelo modelo assistencial a que esses estão vinculados, tendo em vista que a ESF prioriza as ações de prevenção de agravos e promoção da saúde, e a assistência tanto do usuário como de sua família. Sobre isso, há um relato de destaque, o qual remeteu ao conceito mais próximo ao encontrado na literatura.

É o cuidado contínuo. [...] o PSF tem condição de fazer essa longitudinalidade porque a gente começa a atender a família, e devagar você vai atendendo, através das condições de moradia, alimentação; então você começa a perceber se ele melhorou, 0 que geralmente melhora, então você começa a perceber que quem não tem horta passa a ter, começa a ter pé de fruta, começa a reciclar o lixo, então a vida dele, a condição de vida dele vai melhorando, $e$ aqueles que adoecem, você consegue, dependendo do tempo que você fica na unidade, consegue acompanhar (E 13). 
0 relato desse respondente remete a reflexão de que esse cuidado ocorre no seu cotidiano de trabalho, além de que, durante a entrevista, o profissional deixou evidências de que tem claras as propostas da ESF, gosta de atuar nessa área e está há 11 anos inserido nesse modelo assistencial. Ao se cumprir as propostas da ESF há possibilidade de realizar o cuidado longitudinal, sendo fundamental que o profissional conheça de fato os princípios da estratégia e esteja comprometido tanto com suas metas como com as necessidades da comunidade e propósitos da equipe.

0 cuidado ao longo do tempo pode ser visto como um contrato implícito entre profissional e usuário, em que o primeiro assume a responsabilidade permanente para com o indivíduo, de modo que o profissional encaminhe a pessoa para outro nível assistencial, quando a resolutividade estiver além de sua competência e possibilidade. ${ }^{9}$

A longitudinalidade, por se relacionar a resultados positivos na atenção à saúde, deveria ser contemplada em distintas propostas de modelos assistenciais que integram a APS no Brasil, sendo que os elementos favorecedores da longitudinalidade deveriam compor 0 aporte teórico de tais modelos. ${ }^{4}$

\section{Cuidado Longitudinal na Perspectiva da Integralidade da Assistência}

Em uma relação terapêutica duradoura, é fundamental que o profissional compreenda o indivíduo em seus diversos aspectos, ou seja, emocional, mental, espiritual e físico. Sobre isso, alguns profissionais abordaram que a longitudinalidade está diretamente relacionada com a prestação de uma assistência integral, que preza pela visão do ser humano como um todo, provido de sentimentos e com necessidades espećíficas em cada momento de sua vida.

É atender nas fases, ter visão holística, você começa atendendo uma criança e vai acompanhando o desenvolvimento dela ao longo da vida, lembrando que é uma pessoa, e que tem sentimentos e você tem que considerar tudo isso (E11).

É ver desde o nascimento até a morte. Desde a questão nascimento, casamento, ver toda a questão histórica da doença, do diagnóstico, do prognóstico, é ver como indivíduo único, ser tratado na integralidade, em tudo o que ele precisa, na família dele e individualmente como ser único (E19).

No cuidado oferecido ao longo do tempo, o profissional tem a oportunidade de acompanhar o indivíduo no decorrer de seu ciclo de vida, compreendendo melhor o processo saúde/ doença. Desse modo, ao prestar a assistência integral ao usuário, é fundamental que seja considerada a família, visto que, por meio da compreensão do contexto familiar do indivíduo e realidade que está inserido, é possível identificar grande parte de seus problemas; além disso, ao atender às necessidades do núcleo familiar como um todo, chega-se com mais precisão à resolutividade dos problemas de saúde.

Destarte, 0 atendimento integral vai além da estrutura organizacional hierarquizada e regionalizada da assistência em saúde, "se prolonga pela qualidade real da atenção individual e coletiva assegurada aos usuários do sistema de saúde, requer o compromisso com o contínuo aprendizado e com a prática multiprofissional". A integralidade do cuidado ao indivíduo e coletividade se dá por meio da percepção do usuário como ser histórico, social e político, relacionado ao seu contexto familiar, ao meio ambiente e à sociedade que está inserido ${ }^{11: 336}$.

Dentre os quatro atributos essenciais da APS está a integralidade, dessa forma é justificável sua associação com a longitudinalidade, que é considerada 0 atributo mais importante. Neste sentido, as falas dos enfermeiros permitem identificar que para eles o sentido de integralidade é mais no âmbito da assistência direta ao usuário, e sua relação duradoura entre este e o profissional de saúde, remetendo em parte ao significado encontrado na literatura quando se trata da integralidade enquanto princípio da APS, de modo que não envolve outras questões do atendimento integral, como a prestação de todos os atendimentos e serviços de saúde que o usuário necessite.

Aintegralidade implica no fato de as unidades de saúde serem capazes de viabilizar que o usuário seja atendido por todos os tipos de serviços de saúde que necessite, mesmo que isso exija encaminhamento para outros níveis assistenciais, ou seja, ter acesso a serviços secundários para consultas, serviços terciários para manejo definitivo de problemas específicos e para serviços de suporte fundamentais, tais como internação domiciliar e outros serviços comunitários. Além disso, a assistência integral também envolve o reconhecimento, por parte da equipe, a respeito das necessidades de serviços preventivos e curativos, além de evidenciar os problemas que o usuário apresenta, sejam eles funcionais, orgânicos ou sociais. ${ }^{3}$

\section{DE SE N V O LVIME NTO DA LONGITUDINALIDADE DO CUIDADO NO TRABALHO DO ENFERMEIRO E DE SUA EQUIPE}

Do processo de análise de conteúdo se pode identificar que os enfermeiros compreendem a efetivação da longitudinalidade do cuidado sob distintos pontos de vista, dando ênfase na importância da participação da equipe de ESF nesse processo. Tais compreensões são descritas a seguir.

\section{Enfermeiro Acompanhando os Diferentes Ciclos de Vida}

Ao atribuir um conceito para a expressão longitudinalidade, os enfermeiros referiram sobre o cuidado nas diferentes fases da vida, atendendo o usuário na sua 
integralidade e individualidade, por meio de uma assistência duradoura. Do mesmo modo que manifestaram conceitos, evidencia-se, por relatos, que esses estão em conformidade com a prática cotidiana desses profissionais.

O cuidado no decorrer do tempo acontece porque é uma população que sempre viveu aqui, então a gente acompanha sempre, ou a gestante ou uma adolescente, depois engravidou; ou até o idoso, ele tem uma doença crônica e você vai acompanhando (E7).

A gente acompanha o paciente, às vezes é adolescente, aí eu pego ela grávida, mãe, puérpera, cuida da criança. 0 idoso eu já pego na fase da doença, e a gente acompanha ele (E17).

É fundamental que o cuidado seja prestado nos diferentes ciclos de vida, considerando suas particularidades, compreendendo que durante o processo de acompanhamento o profissional terá a possibilidade de visualizar a transição de fases de um usuário ou de sua família, podendo assim intervir no processo saúde/doença. Evidenciou-se nos relatos que o profissional desenvolve a longitudinalidade do cuidado em especial com as fases da vida que exigem mais atenção, ou seja, gestante e adolescente grávida, criança e idoso, os quais têm maior demanda na unidade de saúde. Observou-se, também, que existe mais cobrança e incentivo por parte das secretarias de saúde e gestores.

0 enfermeiro, dentre outras atribuições específicas na equipe da ESF, realiza assistência integral aos indivíduos e famílias, em todas as fases do desenvolvimento humano: infância, adolescência, idade adulta e terceira idade; conforme protocolos ou outras normativas técnicas estabelecidas pelo gestor municipal ou do Distrito Federal, observadas as disposições legais da profissão. ${ }^{12}$

Vale destacar estudo que aponta a longitudinalidade como sendo mais importante na assistência a crianças, idosos, pessoas com menor nível de escolaridade, com alguma condição crônica e em uso de medicações. Do mesmo modo, a satisfação com o profissional de saúde é maior quanto há um contato regular com esse, sendo de suma impor tância que os sistemas de saúde e práticas de atenção primária dediquem esforços adicionais para manter uma relação de continuidade com os usuários mais vulneráveis. ${ }^{13}$

Considerando o propósito de a ESF focalizar seu atendimento na família, chamou a atenção que apenas um profissional salientou a importância de acompanhar a família como um todo, em seus diferentes aspectos na prestação de um cuidado ao longo do tempo.

É muito importante que dentro do PSF você esteja com a família na hora que nasce, e esteja na hora da morte, e mesmo no velório, porque eles têm que sentir que você está integrado com eles, que você se importa (E19).

0 modelo assistencial da ESF permite 0 acompanhamento do indivíduo e de sua família de forma muito próxima. Como se evidenciou no relato, é necessário que a população se sinta integrada com o enfermeiro; desse modo, irá permitir que seu acompanhamento seja realizado com maior eficácia, visto que o estabelecimento de uma boa relação entre profissional e usuário é fundamental para a melhoria da qualidade das ações e de resultados na saúde da população.

Como proposta, a ESF visa estruturar os serviços de saúde, por meio da promoção de uma relação mais estreita entre profissionais e objeto de trabalho, ou seja, mais contíguos das pessoas, famílias e comunidades, com o compromisso de prestar assistência integral e resolutiva a toda população, que tem o acesso ao serviço de saúde garantido, por meio de uma equipe multiprofissional e interdisciplinar. 2,5, 14

\section{A Participação da Equipe no Desenvolvimento da Longitudinalidade do Cuidado}

$\mathrm{Na}$ ESF a articulação das ações de diversos profissionais é indispensável, sendo que a atuação multiprofissional e interdisciplinar é de suma importância para haver a consolidação do trabalho e o alcance dos objetivos do referido modelo assistencial. Assim, a articulação entre as diversas práticas é essencial ao processo de trabalho cotidiano da equipe, devendo ser parte integrante da dinâmica assistencial. ${ }^{15}$

Do mesmo modo, a integração da equipe é inerente para a concretização do cuidado longitudinal na ESF, e, no tocante a esse assunto, os enfermeiros demonstraram satisfação quanto ao trabalho em equipe, sendo que a maior parte dos relatos apontou positivamente esse aspecto.

Toda a equipe participa das ações, do acompanhamento dos pacientes, desde o agente, a técnica em enfermagem, eu, o médico, do PSF, para estar acompanhando também [...] (E6).

A equipe é $100 \%$, até a zeladora participa, é tão boa, que não tem do que reclamar, [...], a gente faz muito o trabalho junto, é claro que você não vai fazer a função do outro, mas vai ajudar (E13).

A equipe é o sentido mesmo da palavra mesmo, equipe, a gente consegue interagir entre nós e com os usuários. A equipe é boa, tem a visão de PSF, essa questão de acompanhar o paciente tem mesmo (E15). 
Por meio da atuação de uma equipe multiprofissional, há maior possibilidade de resolutividade dos problemas de saúde da população, assim como para a promoção da saúde e prevenção de agravos. Pôde-se observar que nos locais em que de fato a equipe é integrada, os enfermeiros não tiveram muitas dificuldades em discorrer sobre o acompanhamento ao longo do tempo, fluindo com naturalidade seus relatos. Ressalta-se aqui que a maior parte dos enfermeiros afirmou que a equipe é colaborativa, porém é possível perceber a participação mais efetiva do ACS, considerado por eles como essencial para haver a longitudinalidade do cuidado junto aos usuários.

Os ACS fazem a visita e passam para a gente, que eles são sempre o primeiro contato com $o$ paciente, então eles passam para a gente tentar dar continuidade do trabalho (E6).

É muito mais através da ação do ACS, são 700 e poucas famílias, você não tem perna para ficar indo continuamente; ele acompanha, tem famílias de risco, e ele está passando para a gente a necessidade da equipe ir visitar (E10).

Em uma equipe de ESF cada membro tem suas funções específicas, e, sendo o ACS responsável por visitar mensalmente as famílias da área de abrangência, é a pessoa que mais conhece a realidade da população. Quando adequadamente capacitado, tem condições de elencar as prioridades e levar as diversas situações de saúde para os demais membros da equipe, para que juntos possam discutir e planejar a melhor resolutividade para cada caso. Relatos permitiram evidenciar que quem efetivamente tem um acompanhamento ao longo do tempo da população é o enfermeiro, aliado aos ACS, os quais estão mais diretamente envolvidos com essa prática.

Estudo aponta que enfermeiros articulam suas ações de forma mais intensa com o ACS, especialmente pela proximidade entre ambos no cotidiano profissional, ${ }^{15}$ corroborando os dados encontrados no presente trabalho. Assim, o ACS é um profissional de extrema relevância na ESF, o qual deve residir na área que atua e vivenciar a realidade local, interagindo com valores, linguagens, problemas, alegrias, satisfações e insatisfações da população. Dessa forma, o ACS tem o papel fundamental de realizar o intercâmbio entre os usuários e a equipe de saúde, identificando as necessidades de saúde, visando à busca de intervenções multiprofissionais no intuito de melhorar a qualidade de vida e saúde da população adscrita. ${ }^{16}$

A participação dos demais membros da equipe na atuação interdisciplinar é menor, de modo que o médico é visto por enfermeiros como o profissional menos integrado com as atividades em equipe, atuando em um modelo tradicional, por meio de consultas na unidade de saúde, realizando ações junto à comunidade apenas em visitas domiciliárias no atendimento aos casos mais graves.

O médico vai, faz a visita quando solicitado, mas não tem esse acompanhamento tão direto, não tem aquele vínculo maior, não desenvolve (E1).

A equipe não acompanha, o médico não se envolve, fica mais na demanda mesmo [...] (E8).

A literatura tem apontado que os médicos que atuam na ESF ainda têm uma formação acadêmica fragmentada e basicamente hospitalar, e, além disso, têm deficiência na educação permanente voltada ao reconhecimento dos problemas da realidade local, dificuldades na execução do trabalho interdisciplinar, além de falta de perfil para exercer um atendimento de forma integral à população adscrita. ${ }^{17,} 18$ Percebe-se que a atuação do médico, de maneira geral, não vai ao encontro das propostas da ESF, as quais priorizam ações de prevenção de agravos, promoção à saúde, e fundamentalmente, trabalho em equipe.

\section{CONSIDERAÇÕES FINAIS}

A despeito de algumas limitações do presente estudo, como, por exemplo, a falta de conhecimento prévio dos enfermeiros sobre a longitudinalidade do cuidado, seu significado e os aspectos que a envolvem, consideramos que, após explicação inicial, os respondentes conseguiram compreender o conceito e tecer comentário sobre este em relação a sua prática, abarcando de forma satisfatória os objetivos do estudo e permitindo uma compreensão sobre o tema, assim como a sua configuração no cotidiano de trabalho não somente do enfermeiro, mas também de toda equipe de saúde da família.

A concepção dos enfermeiros sobre o termo longitudinalidade está próxima ao conceito encontrado na literatura, perpassando pela questão de ser uma relação que ocorre ao longo do tempo, estando diretamente associada a outro atributo da APS, a integralidade na assistência, que pressupõe ver a pessoa na sua individualidade e como ser social.

Quanto ao desenvolvimento da longitudinalidade no cotidiano de trabalho, os profissionais ressaltaram pontos que vêm ao encontro das propostas do modelo assistencial em que está atuando, a ESF, como o acompanhamento dos usuários nas diferentes fases da vida, a assistência integral ao 
indivíduo e família, considerando seu contexto biopsicossocial, assim como a atuação por meio de ações de prevenção de agravos e promoção da saúde, visando resultados positivos na situação de saúde da população.

No que tange ao trabalho na equipe de ESF, percebeu-se que, de um modo geral, a equipe é participativa e que, quando é integrada, a longitudinalidade do cuidado ocorre com mais facilidade e eficácia. 0 ACS foi considerado o profissional mais importante para a ocorrência do acompanhamento longitudinal, por ter maior conhecimento e contato com a população adscrita, podendo assim identificar as prioridades de atendimento da equipe. Entretanto, o profissional que menos participa da atuação interdisciplinar, na concepção de enfermeiros, é o médico, o qual fica restrito às ações de caráter curativo.

Com a realização do estudo se pode reforçar dados encontrados em outros estudos sobre a longitudinalidade do cuidado, ou seja, a necessidade de haver uma relação duradoura entre profissional e usuário, acompanhando os diferentes ciclos de vida, conhecendo sua individualidade, o que viabiliza a elaboração de intervenções mais eficazes, chegando à resolutividade dos problemas com maior rapidez.

0 presente estudo serve de subsídio para que outras pesquisas sejam realizadas nesse sentido, pois a longitudinalidade tem benefícios comprovados na literatura, porém ainda é um tema pouco discutido e explorado, especialmente no Brasil. Para tanto, é necessário que seja investigada não somente a atuação do enfermeiro, mas também a realidade dos demais membros da equipe da ESF, permitindo que se identifiquem suas falhas e sucessos, com vistas à melhoria da qualidade da assistência, propiciando que essa possa, cada vez mais, ter um caráter longitudinal no âmbito da saúde da família.

Por fim, o estudo aponta a necessidade de os enfermeiros fazerem maiores reflexões sobre sua prática e envidarem esforços para deixar de centrar suas ações na doença e na organização de uma assistência que tem como foco o profissional médico e o atendimento à demanda curativa. Nesse âmbito, haverá a possibilidade de se constituir um trabalho assistencial do enfermeiro com vistas ao cuidado em suas distintas manifestações, com impactos positivos tanto para o profissional enfermeiro e demais membros da equipe de saúde da família, como para a estruturação do próprio modelo assistencial em questão, e, principalmente, para a saúde dos usuários.

\section{REFERÊNCIAS}

1. Silva K, Sena RR, Grillo MJC, Horta NC. Formação do enfermeiro: desafios para a promoção da saúde. Esc. Anna Nery. 2010; 14(2): 36876.

2. Rosa WAG, Labate RC. Programa Saúde da Família: a construção de um novo modelo de assistência. Rev Latino-am Enfermagem. 2005 nov/ dez; 13(6):1027-034.

3. Starfield B. Atenção primária: equilíbrio entre necessidades de saúde, serviços e tecnologia. UNESCO/ Ministério da Saúde; 2002. 726p.

4. Cunha E. Vínculo longitudinal na atenção primária: avaliando os modelos assistenciais do SUS. 2009. [tese]. Rio de Janeiro: Escola Nacional de Saúde Pública Sergio Arouca; 2009. 169 p.

5. Macinko J, Almeida C, Oliveira E, Sá P. Organization and delivery of primary health care services in Petrópolis, Brazil. Int J Health Plann Mgmt. 2004; 19:303-17. [citado 2010 mar 06. Disponível em: http://www.opas.org.br/observatorio/Arquivos/Destaque82.pdf.

6. Schimith MD, Lima MADS. 0 enfermeiro na Equipe de Saúde da Família: estudo de caso. Rev Enferm UERJ. abr/jun 2009;17(2): 252-56.

7. Bardin L. Análise de conteúdo. Lisboa: Ed 70; 2008.

8. Haggerty JL, Reid RJ, Freeman GK, Starfield BH, Adair CE, McKendry R. Continuity of care: a multidisciplinary review. BMJ 2003; 327: $1219-221$

9. Saultz JW. Defining and measuring Interpersonal continuity of care. Annals of Family Medicine 2003; 1(3):134-45.

10. Pastor-Sánchez R, Miras AL, Fernández MP, Camacho RG. Continuidad y longitudinalidad en medicina general en cuatro países Europeos. Rev Española de Salud Publica 1997; 71: 479-85.

11. Machado MFAS, Monteiro EMLM, Queiroz DT, Vieira NFC, Barroso MGT. Integralidade, formação de saúde, educação em saúde e as propostas do SUS: uma revisão conceitual. Cienc. Saude Colet. 2007. 12(2): 335-42. [citado 2010 maio 24. Disponível em: http:// www.scielo.br/pdf/csc/v12n2/a09v12n2.pdf .

12. Portaria $n^{\circ} 648$, de 28 de março de 2006: Aprova a Política Nacional de Atenção Básica, estabelecendo a revisão de diretrizes e normas para a organização da atenção básica para o Programa Saúde da Família (PSF) e o Programa Agentes Comunitários de Saúde (PACS). Brasília(DF); 2006.

13. Nutting PA, Goodwin MA, Flocke SA, Zyzandki SJ, Stage KC. Continuity of primary care: to whom does it matter and when? Ann Fam Med 2003; 1:149-55. 
14. EscorelS, Giovanella L, Mendonça MHM, Senna MCM. O Programa de Saúde da Família e a construção de um novo modelo para a atenção básica no Brasil. Pan American J Public Health 2007; 21 (2/3):164-76. [citado 2010 fev 27]. Disponível em: http://www.scielosp.org/pdf/rpsp/ v21n2-3/11.pdf ..

15. Colomé ICS, Lima MADS, Davis R. Visão de enfermeiras sobre as articulações das ações de saúde entre profissionais de equipes de saúde da família. Rev Esc Enferm USP. 2008; 42(2): 256-61.

16. Brand C, Antunes R, Fontana R.. Satisfações e insatisfações no trabalho do agente comunitário de saúde. Cogitare Enferm.2010. 15(1): 40-7.

17. Santos MAM, Cutolo LRA. A interdisciplinaridade e o trabalho em equipe no Programa de Saúde da Família. Arq Catarin. Med. 2003; 32(4): 65-74.

18. Goncalves RJ, Soares RA, Troll T, Cyrino EG. Ser médico no Programa de Saúde da Família: formação acadêmica, perspectivas e trabalho cotidiano. Rev Bras Educ Med. 2009. 33(3): 382-92.

\section{NOTA}

${ }^{\text {a}}$ Resultados extraídos da dissertação de mestrado: Percepções de enfermeiros sobre a longitudinalidade em seu trabalho na Estratégia Saúde da Família, 2010, Mestrado em Enfermagem, Universidade Estadual de Maringá 